\title{
LAND USE/LAND COVER CHANGE AND ENVIRONMENTAL EFFECTS IN THE NORTHEASTERN QINGHAI-TIBET PLATEAU FROM 1980 TO 2015
}

\author{
J. Y. Zhao ${ }^{1, *}$, Q. Song ${ }^{1}$, M. Du ${ }^{1}$, G. R. Li ${ }^{1}$, J. Yang ${ }^{2}$ \\ ${ }^{1}$ Department of Geologic Engineering, Qinghai University, Xining 810016, China;zhaojianyun1981@163.com \\ ${ }^{2}$ Meteorological Station of Gangcha County, Qinghai Haibei 812300, People’s Republic of China, 962364889@qq.com
}

KEY WORDS: NDVI, Multi-scale, spatio-temporal variations, vegetation cover, Qinghai-Tibet Plateau

\begin{abstract}
:
The Qinghai-Tibet Plateau ecosystem is sensitive and fragile, the grassland degradation and soil erosion in the plateau are still increasing. In this paper, we conducted a quantitative study to clarify the characteristics of land use/land cover change, the driving factors, and the environmental effects in the plateau. We focused on the northeastern Qinghai-Tibet Plateau as an example, and created land use change matrices and determined the relative change rate, vegetation cover, and environmental quality index using land use data and $\mathrm{NDVI}_{3 \mathrm{~g}}$ data from 1980 to 2015 . The results show that there were significant differences in land use/land cover change in the study area around 2000, while the farmland did not increase significantly, and the water areas exhibited a decreasing trend initially followed by an increasing trend, the unused land first increased and then decreased, and residential areas increased significantly after 2000. The relative change rate of the grassland was the largest between 1980 and 2015, while most of the grassland was converted into farmland, residential land, and unused land. In addition, grassland degradation increased significantly. Considerable spatial heterogeneity in vegetation and land use/land cover was observed in the study area. The vegetation cover decreased in some areas due to the grassland degradation, however, the others areas showed improvements due to the influences of policies and climate change. The environmental index and ecological service value of the study area declined and the environment deteriorated during the study period.
\end{abstract}

\section{INTRODUCTION}

The five assessment reports of the Intergovernmental Panel on Climate Change (IPCC) between 1990 and 2013 clearly indicated that a worldwide warming trend has occurred for nearly a hundred years and this trend has been particularly significant during the past 50 years(Zhao, Luo, and Huang 2018). Many problems have been caused by global warming, such as shrinking of the cryosphere, impacts on biodiversity, desertification, and frequent extreme weather and these effects have influenced the ecological balance and sustainable development(Jevrejeva, Moore, and Grinsted 2010; Zhao, Ran, and Moore 2016). Land is an important resource for human survival and development and land use and land cover change (LUCC) has a large impact on regional ecosystems and their biodiversity by changing the ecosystem types, functions, and structures, which in turn leads to a series of ecological and environmental problems. This topic has become an important component of current global change research (Li et al. 2017; Luo and Tao 2018; Wang 2018; Xu 2017; Zhang et al. 2018).

Many scholars have conducted LUCC research and achieved good results regarding land use change monitoring, the determination of the underlying mechanisms and driving forces, as well as model prediction. For example, Ruelland used aerial images to monitor LUCC in the Sahel; it was determined that the farmland areas had increased significantly and the forest areas had decreased significantly during the past 50 years(Ruelland et al. 2011). Jiang et al. investigated LUCC and its driving force in Xishuangbanna, China and found that the main driving factors of LUCC in this region were population density, annual average temperature, grain yield, and economic density(Jiang et al. 2011). Freitas et al. conducted a study in the Uruguay Basin (Brazil) and simplified LUCC modeling by using multiple complex land use/land cover processes based on a system dynamics model(Freitas et al. 2018). At present, the changes in the regional climate, soil, biodiversity, and other factors caused by LUCC and the impact on ecosystems are topics of wide concern and are being researched(Cheng et al. 2008; Flamenco-Sandoval, Ramos, and Masera 2007).

The Qinghai-Tibet Plateau is often called the third pole in the world because of its unique natural geography and its important role in regional climate regulation and in soil, water, and species conservation, as well as an important barrier to regional ecological security. However, the area's ecosystem is sensitive and fragile and problems such as grassland degradation and soil erosion are increasing. The area of desertified land and the degree of desertification have been on the rise( $\mathrm{Li}$ et al. 2018; Zhang et al. 2013). To date, research on LUCC on the Qinghai-Tibet Plateau has focused on the spatial and temporal characteristics, the landscape patterns, and the driving mechanism of the typical regions but there has been a lack of quantitative research on the environmental effects and recent monitoring of the spatiotemporal changes. In this study, Qinghai in the northeastern part of the plateau is used as an example to determine the characteristics of LUCC change from 1980 to 2015 and its driving factors and environmental effects.

\section{MATERIALS AND METHODS}

\subsection{Study Area}

The study area is located in the northeastern part of the Tibetan Plateau (Fig. 1) at $89^{\circ} 35^{\prime}-103^{\circ} 04^{\prime}$ longitude and $31^{\circ} 39^{\prime}-39^{\circ} 19^{\prime}$ latitude. The extent of the study area is about $1200 \mathrm{~km}$ from east to west and $800 \mathrm{~km}$ from north to south and it covers an area of about $721,200 \mathrm{~km}^{2}$; this represents $7.51 \%$ of China's land area. The study area is adjacent to Gansu, Sichuan, Tibet, and Xinjiang province. The average elevation of the

\footnotetext{
* Corresponding Author
} 
research area is greater than $3000 \mathrm{~m}$; the highest elevation of $6860 \mathrm{~m}$ is the peak of Bukada and the lowest elevation is 1650 $\mathrm{m}$ in Xiachuankou in Minhe County. The elevation is lower in the west and higher in the east. Qinghai is the water tower of China and the source of the Yangtze River, the Yellow River, and the Lancang River. There are several inland water systems

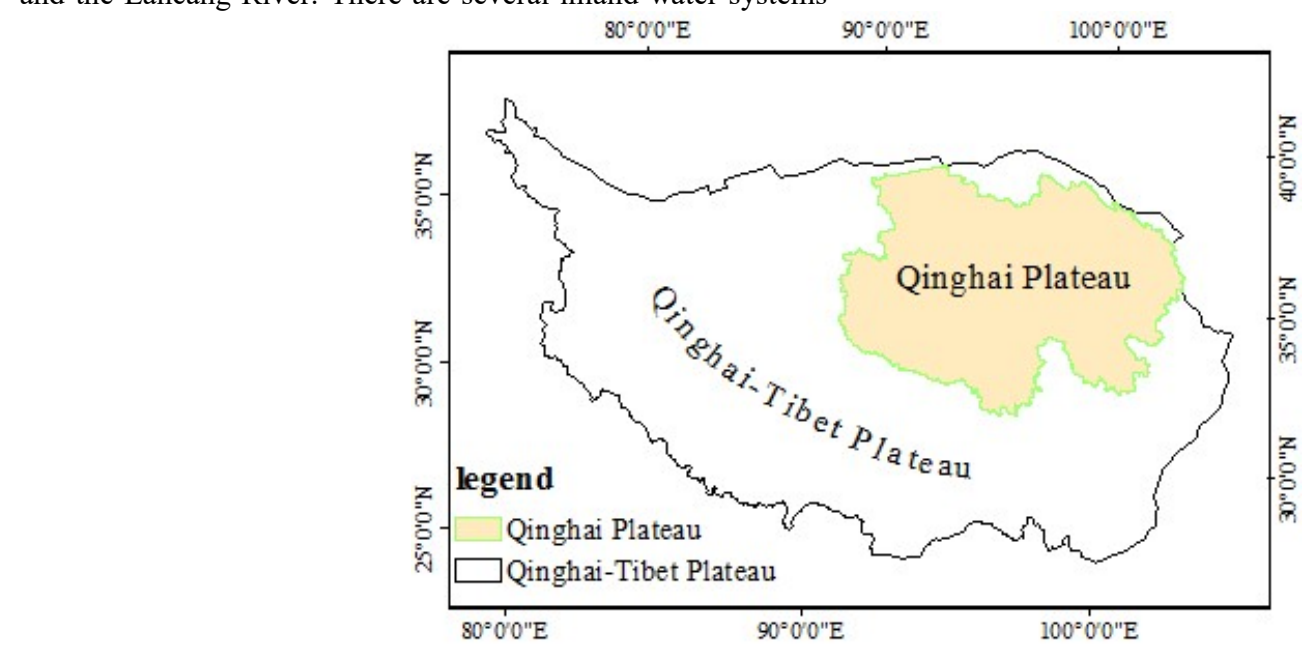

Fig.1 the Location of the Study area such as the Qaidam Basin, Qinghai Lake Basin, and Qilian Mountain. There are many lakes with a combined area of $12855.8 \mathrm{~km}^{2}$, making the area second only to Tibet in terms of the lake area. The groundwater resources in the study area are abundant and there are many glaciers.
The annual average temperature is below $0{ }^{\circ} \mathrm{C}$ in the north and south of the research area and between 0 and $8{ }^{\circ} \mathrm{C}$ in the central area. The temperature differences between daytime and nighttime are large; the highest average temperature occurs in July and the lowest occurs in January. The average annual rainfall is $200-500 \mathrm{~mm}$ and occurs predominantly from June to September. The rainfall is unevenly distributed and decreases from southeast to northwest. The climate is affected by various factors such as the Qinghai-Tibet Plateau, atmospheric circulations, and the topography and the area has a continental climate. There are various types of land use/land cover in the area with significant plateau zonality. Land used for grazing livestock is mainly located in the southern, western, and northern regions. The farmland is mainly concentrated in the Hehuang area, the Qaidam Basin, and the Gonghe Basin, whereas forest land is mainly distributed in the eastern and southeastern regions. The vegetation types include coniferous forest, broad-leaved forest, shrub, grassland, meadow and alpine vegetation.

\subsection{Data sources}

The following data sources were used in this study:

1) 1:100,000 land use data of China: The data were obtained from the Resource and Environmental Science Data Center at the Chinese Academy of Sciences (http: //resdc.cn). The dataset was developed by the National Science and Technology Support Program and the Innovation Project at the Chinese Academy of Sciences. The data are based on Landsat interpretation, which is currently the most accurate remote sensing-based land cover data product in China. The dataset includes six periods of land cover data: the late 1970s (1980), the late 1980s (1990), 2000, 2005, 2010, and 2015.

2) AVHRR GIMMS $\mathrm{NDVI}_{3 \mathrm{~g}}$ data: We used the National Oceanic and Atmospheric Administration (NOAA) Advanced Very High Resolution Radiometer (AVHRR) data and the Global Inventory Modeling and Mapping Studies (GIMMS) normalized difference vegetation index (NDVI) third generation $\left(\mathrm{NDVI}_{3 \mathrm{~g}}\right)$ global coverage product dataset. The data corrections that had been applied to the data included orbital offset, atmospheric water vapor, radiation, aerosols, cloud removal, and geometric distortion(Pinzon and Tucker 2014). The spatial resolution of the $\mathrm{NDVI}_{3 \mathrm{~g}}$ data is approximately $8 \mathrm{~km}$. Pinzon et al. found that the measurement uncertainty of the $\mathrm{NDVI}_{3 \mathrm{~g}}$ data was \pm 0.005 , which makes the data suitable for the study of the seasonal and interannual variations of vegetation(Pinzon and Tucker 2014). The Savitzky-Golay and wavelet adaptive noise reduction methods were used to reduce the noise in the data(Zhao and Zhang 2018).

3) Zoning data: The data were obtained from the Resource and Environmental Science Data Center at the Chinese Academy of Sciences (http: //resdc.cn). This dataset was used to clip out and project the remote sensing data to obtain the 1:100,000 land use/land cover data and the GIMMS $\mathrm{NDVI}_{3 \mathrm{~g}}$ data in the study area.

\subsection{Methods}

\subsubsection{Land Use/Land Cover Change Matrix}

A land use/land cover change matrix describes the changes in land use/land cover in two different periods; it is commonly used in land use/land cover research. The change matrix is defined as:

$$
S_{i j}=\left[\begin{array}{cccc}
S_{11} & S_{12} & \ldots & S_{1 n} \\
S_{21} & S_{22} & \ldots & S_{2 n} \\
\ldots & \ldots & \ldots & \ldots \\
S_{n 1} & S_{n 2} & \ldots & S_{n n}
\end{array}\right]
$$

where $S_{i j}$ is the area of the land type $i$ that was converted to the land type $j$ and $n$ is the number of land use/land cover types.

2.3.2 Relative rate of land use/land cover change

This parameter describes the relative rate of change of a land type over a certain period of time; it reflects the spatial and temporal differences in the changes in different land types and it is defined as:

$$
W_{k}=\frac{\left|s_{j}^{k}-s_{i}^{k}\right|}{\sum_{k=1}^{n}\left(\left|s_{j}^{k}-s_{i}^{k}\right|\right)}
$$


where $W_{k}$ is the relative rate of change for the land type $k, s_{j}^{k}$ is the area of the land type $k$ in the second period, $s_{i}^{k}$ is the area of the land type $k$ in the first period, $n$ is the number of land use types, and the value of $W_{k}$ indicates the extent of land use type changes during the study period.

\subsubsection{Fractional Vegetation Cover}

The fractional vegetation cover (FVC) is the ratio of the vertical projected area of the vegetation on the ground to the total area; it is an important indicator of regional environmental changes and is estimated using a pixel-based binary model:

$$
F V C=\frac{N D V I-N D V I_{\text {min }}}{N D V I_{\text {max }}-N D V I_{\text {min }}}
$$

where $N D V I$ is the vegetation index; $N D V I_{\max }$ and $N D V I_{\min }$ are the maximum and minimum value of the NDVI in the research area.

2.3.4 Environmental Quality Index

The environmental quality index comprehensively considers the ecological service value and area ratio of each land type and quantitatively describes the changes in the environmental quality resulting from land use/land cover change(Batu, Ding, and Li 2018); it is defined as:

$$
E V_{t}=\sum_{k=1}^{n} s^{k} \times c^{k} / T S
$$

where $E V_{t}$ is the environmental quality index of the research area, $S^{k}$ is the area of the land type $k, T S$ is the total area of all land types, $c^{k}$ is the environment quality parameter of different land use types based on the different ecosystem service

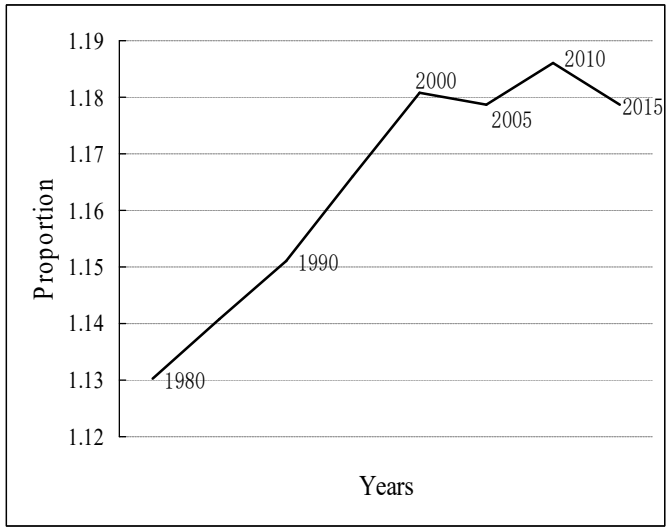

(a)Farmland

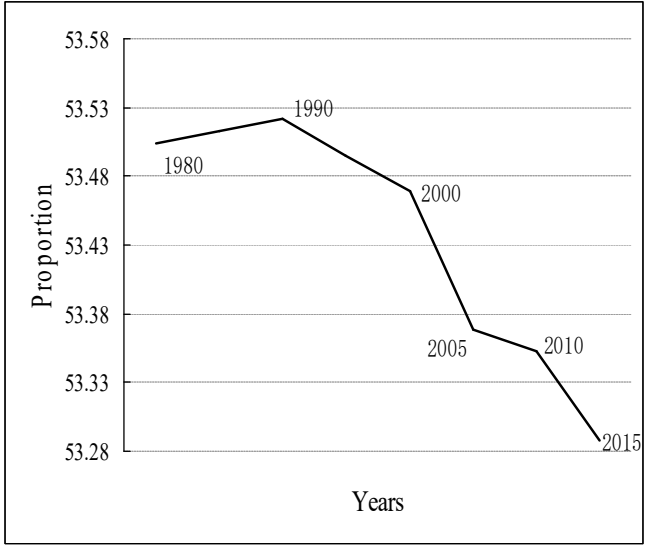

(c)Grassland values in the Qinghai-Tibet Plateau(Xie et al. 2003) ( the details are shown in Table 1), and $n$ is the number of land use types.

Tab.1 Environment Quality Parameter of Different Land Use Types

\begin{tabular}{ccc}
\hline $\begin{array}{c}\text { Land } \\
\text { use/cover } \\
\text { type }\end{array}$ & $\begin{array}{c}\text { Ecological service } \\
\text { value }\left(\text { yuan } / \mathrm{hm}^{2}\right)\end{array}$ & $\begin{array}{c}\text { Eco-environmental } \\
\text { quality parameters }\end{array}$ \\
\hline Farmland & 4341.2 & 0.07 \\
Forestland & 13462.7 & 0.22 \\
Grassland & 3512.6 & 0.06 \\
Water & 40676.4 & 0.64 \\
Other Land & 371.4 & 0.01 \\
\hline
\end{tabular}

\section{RESULTS}

The results of the LUCC analysis indicates that the farmland is mainly distributed in the eastern part of the study area, the forest land occurs mainly in the northern part of the Qilian Mountains and the southern part of the Qingnan Plateau, the grassland is mainly distributed in the periphery of Qinghai Lake and in most of the Qingnan Plateau, and the unused land is mainly distributed in the Qaidam Basin area in the northwestern part of the study area. The grassland comprises the largest area of all land types. The proportion of unused land is high; this consists of mainly sandy land and areas in the Gobi desert. The land use/land cover classification based on the 1:100,000 land use data in the research area in 1980, 1990, 2000, 2005, 2010, and 2015 and the time series of the proportion of the land use/land cover types is shown in Figure 2.

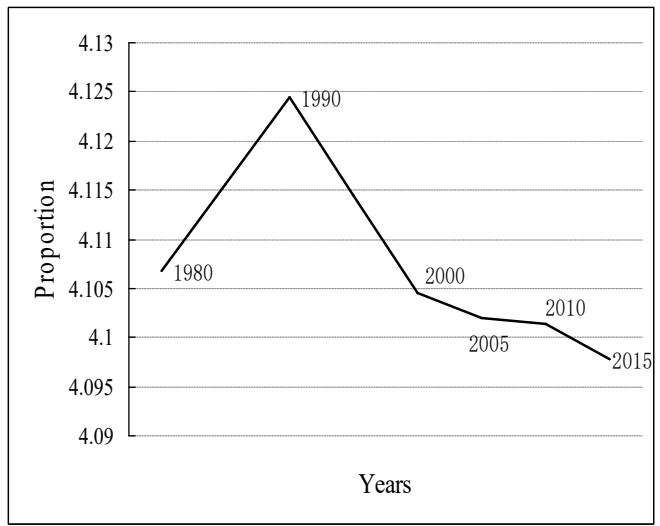

(b) Forestland

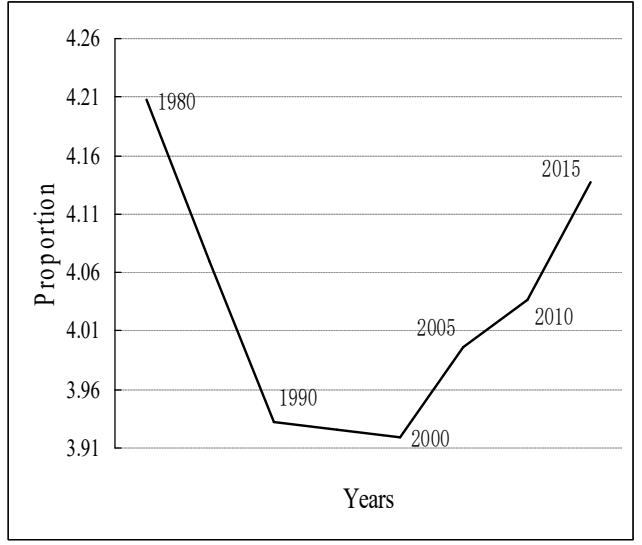

(d) Water 


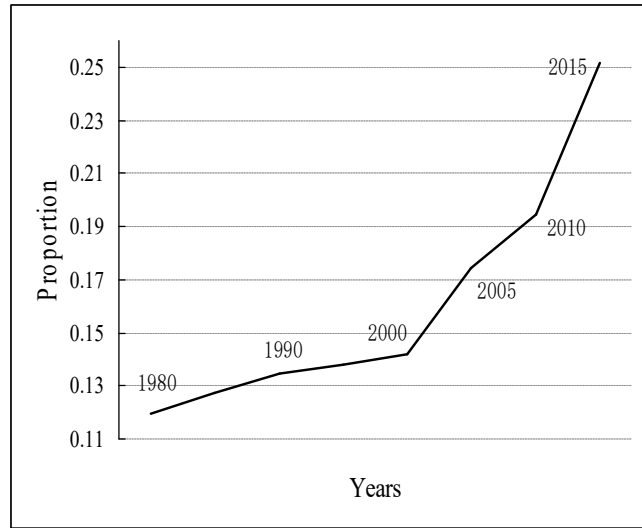

(e)Residential land

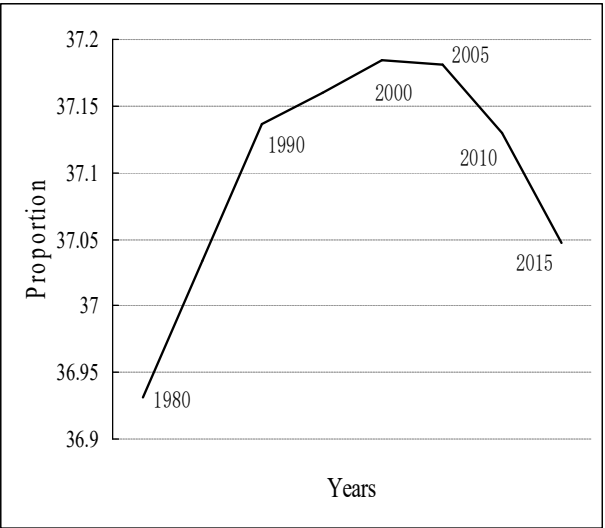

(f) Unusedland

Fig.2 Time Series of the Proportion of the Land Use/Land Cover Types (\%)

The results show that the proportion of farmland in the study area has increased over the past 35 years and the growth rate has slowed down and gradually stabilized since 2000 . The forest land and grassland are have decreased and the decrease was more significant for the grassland. The water area first decreased and then increased after 2000. The residential land areas have gradually increased, whereas the unused land area first increased and then decreased since 2000. This illustrates that there were differences in the trends of the land types but there was a shift that occurred in the overall land use/land cover around 2000 . We used 2000 as a threshold and determined the changes in the proportion of land use/land cover types during 1980-2000, 2000-2015, and 1980-2015 (Figure 3); we then calculated the relative change rate of the land use/land cover from 1980 to 2015 using Eq. (2). The results are shown in Figure 4.

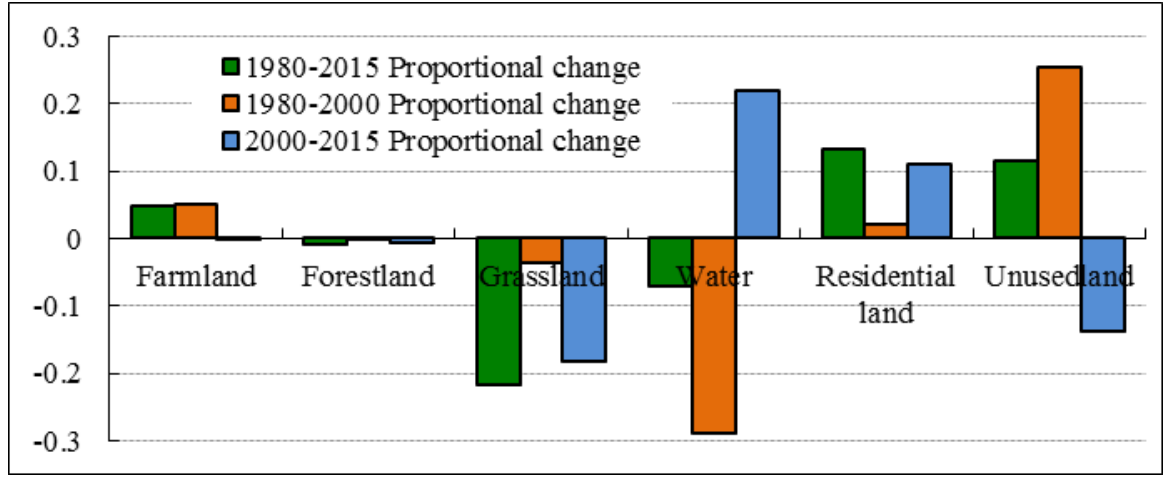

Fig.3 Changes in the Proportion of Land Use/Land Cover Types during Different Periods (\%)

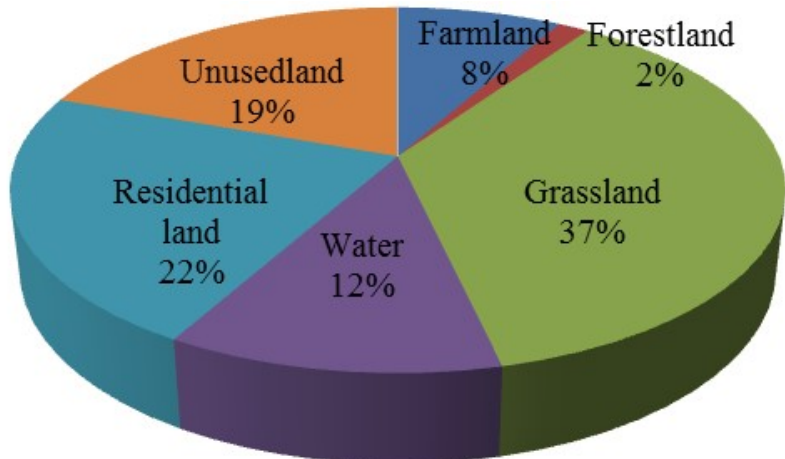

Fig.4 Relative Change Rate of the Land Use/Land Cover

The results show that the increase in the farmland and unused land in the study area occurred mainly between 1980 and 2000. In the past 35 years, the grassland area has decreased and the residential land area has increased and this trend has become more apparent after 2000 . The relative change rate was largest for the grassland. In order to clarify the characteristics of the changes in the land types, land use change matrices were created for the periods of 1980- 2000 and 2000-2015. The results are shown in Tables 2 and 3. 
Tab.2 Land Use Change Matrice for the period of 1980- $2000\left(\mathrm{~km}^{2}\right)$

\begin{tabular}{|c|c|c|c|c|c|c|c|}
\hline Land Cover Type & Farmland & Forestland & Grassland & Water & Residential land & Unusedland & Total \\
\hline Farmland & 7726 & 18 & 439 & 18 & 0 & 15 & 8216 \\
\hline Forestland & 0 & 28471 & 79 & 10 & 0 & 2 & 28562 \\
\hline Grassland & 8 & 68 & 371224 & 522 & 2 & 251 & 372075 \\
\hline Water & 76 & 7 & 149 & 26777 & 0 & 266 & 27275 \\
\hline Residential land & 38 & 4 & 34 & 11 & 831 & 69 & 987 \\
\hline Unusedland & 17 & 10 & 396 & 1940 & 0 & 256392 & 258755 \\
\hline Total & 7865 & 28578 & 372321 & 29278 & 833 & 256995 & 695870 \\
\hline
\end{tabular}

Tab.3 Land Use Change Matrice for the period of 2000-2015 $\left(\mathrm{km}^{2}\right)$

\begin{tabular}{cccccccc}
\hline Land Cover Type & Farmland & Forestland & Grassland & Water & Residential land & Unusedland & Total \\
\hline Farmland & 8028 & 8 & 154 & 0 & 0 & 12 & 8202 \\
Forestland & 4 & 28500 & 11 & 0 & 0 & 0 & 28515 \\
Grassland & 68 & 28 & 370384 & 9 & 3 & 321 & 370813 \\
Water & 21 & 24 & 417 & 26695 & 9 & 1627 & 28793 \\
Residential land & 95 & 2 & 254 & 28 & 971 & 400 & 1750 \\
Unusedland & 0 & 0 & 855 & 543 & 4 & 256395 & 257797 \\
Total & 8216 & 28562 & 372075 & 27275 & 987 & 258755 & 695870 \\
\hline
\end{tabular}

The results indicate that between 1980 and 2000, the area of grassland converted to cultivated land was $439 \mathrm{~km}^{2}$, the area converted to unused land was $396 \mathrm{~km}^{2}$, and the area of unused land converted to grassland was $251 \mathrm{~km}^{2}$. From 2000 to 2015 , the total area of grassland converted to cultivated land and residential land was $408 \mathrm{~km}^{2}$, the area converted to unused land was $855 \mathrm{~km}^{2}$, and the area of unused land converted to grassland was $321 \mathrm{~km}^{2}$.
We used the $\mathrm{NDVI}_{3 \mathrm{~g}}$ data from 1982 and 2015 for the growing season (July-August) in the study area to calculate the FVC of the changed and unchanged areas in both years using Eq. (3); the results are shown in Table 4. The environmental quality index and ecological service value of the land types in 1980 and 2015 were calculated using Eq. (4) and the data in Table 1; the results are shown in Table 5.

Tab.4 FVC of the Changed and Unchanged Areas in 1982 and 2015

\begin{tabular}{cccc|ccc}
\hline \multirow{2}{*}{ Values } & \multicolumn{3}{c}{1982} & \multicolumn{3}{c}{2015} \\
\cline { 2 - 6 } & $\mathrm{NDVI}_{\min }$ & $\mathrm{NDVI}_{\max }$ & $\mathrm{FVC}$ & $\mathrm{NDVI}_{\min }$ & $\mathrm{NDVI}_{\max }$ & $\mathrm{FVC}$ \\
\hline Changed areas & 0.019 & 0.860 & 0.3138 & \multirow{2}{*}{0.020} & 0.830 & 0.3811 \\
Unchanged areas & & & 0.3818 & & 0.4086 \\
\hline
\end{tabular}

Tab.5 Environmental Quality Index and Ecological Service Value in 1980 and 2015

\begin{tabular}{ccccccccc}
\hline Values & Years & Farmland & Forestland & Grassland & Water & Otherland & Total \\
\hline \multirow{2}{*}{ Environmental Quality Index } & 1980 & 0.0008 & 0.0090 & 0.0321 & 0.0269 & 0.0037 & 0.0725 \\
& 2015 & 0.0008 & 0.0090 & 0.0320 & 0.0265 & 0.0037 & 0.0720 \\
\hline \multirow{2}{*}{ Ecological Service Value(Ten thousand yuan) } & 1980 & 3414.354 & 38473.700 & 130781.500 & 119092.400 & 9575.732 & 301337.686 \\
& 2015 & 3560.652 & 38388.890 & 130251.800 & 117119.600 & 9639.576 & 298960.518 \\
\hline
\end{tabular}

It is observed that the FVC increased from 1982 to 2015 , regardless of whether the area was a change area or a nonchange area and the increase was higher for the changed area. From 1980 to 2015, the environmental quality and ecological service value of the study area decreased and this was attributed mainly due to the decline in the environmental quality of the grassland and water areas.

\section{DISCUSSIONS}

The Tibetan Plateau is one of the most sensitive regions to global climate change (Gou et al. 2010; Liu and Chen 2015; Zhang et al. 2015) and LUCC reflects the effects of climate change and human activities and affects various fragile ecosystems on the Qinghai-Tibet Plateau. Therefore, an investigation of LUCC and its environmental effects in the northeastern part of the plateau is important to clarify the direction and trend of LUCC in order to understand the mechanism of alpine ecosystem change and guide approaches to achieve harmonious and sustainable development in the plateau. The FVC and environmental index provide insights into the driving mechanisms of LUCC in the research area allow for the quantitative evaluation of the changes in environmental quality.

Land use/land cover in the study area has changed significantly since 2000 . For example, the area of cultivated land has not increased significantly and the area of unused land has increased; this is closely related to the implementation of the policy of returning farmland to forests (grass) and to 
promote grazing of grasslands in Qinghai. According to information provided by the Forestry Department of Qinghai Province, the policy of returning farmland to forests (grass) and promoting grazing of grasslands implemented in the study area was in the pilot stage from 2000 to 2001, was fully implemented in 2002-2006, and was completed in 2007-2015. From 2000 to 2015 , the area that changed from farmland to forests and grassland was $1934.3 \mathrm{~km}^{2}\left(1740.1 \mathrm{~km}^{2}\right.$ for forests and $194.2 \mathrm{~km}^{2}$ for grasslands) and this change occurred in 44 counties (states, districts, and farms), 327 townships, 3911 administrative villages, and 296,200 rural households. This affected 1,3555,000 farmers and herdsmen, indicating that the national policies have effectively driven the LUCC in the study area.

Grasslands represent the land type with the largest relative change in land type. The area of grassland change between 1980 and 2000 was $1,097 \mathrm{~km}^{2}$, of which $43 \%\left(473 \mathrm{~km}^{2}\right)$ was converted into farmland or residential land and $36 \%\left(396 \mathrm{~km}^{2}\right)$ was converted to unused land. Cultivated land or residential land is a land type with intense human activity and the results indicated that human activity was the driving factor for LUCC in the study area. However, in absolute terms, there was no significant increase in LUCC before and after 2000. The relative and absolute numbers of grassland areas converted to unused land increased significantly, that is, the grassland in the study area showed a trend of continuous degradation; This is in agreement with the results of a study on the degradation of alpine grassland ecosystems on the Qinghai-Tibet Plateau(Cao et al. 2013; Cui et al. 2007; Harris 2010; Li et al. 2013; Liu et al. 2015; Tang et al. 2014).

The overall FVC in the study area increased between 1982 and 2015 and the increase was larger in areas of LUCC. Temperature and precipitation are important climate factors driving vegetation growth(Cannone, Sgorbati, and Guglielmin 2007; Hoffmann and Jackson 2000; Richardson et al. 2013); the average temperature and precipitation in the study area increased from 1982 to 2015 (Figure 5) and the temperature increase was particularly significant. Therefore, against the background of climate warming and humidification, the vegetation growth status has improved and the vegetation cover has also improved. However, taking into account the continuous degradation of grasslands, the increase in vegetation cover of the grasslands also indicates that there is large spatial heterogeneity of vegetation and land cover in the study area, i.e., grassland degradation has reduced the vegetation cover in some areas but in other areas, the vegetation cover has increased significantly due to the influences of policies and climate change.

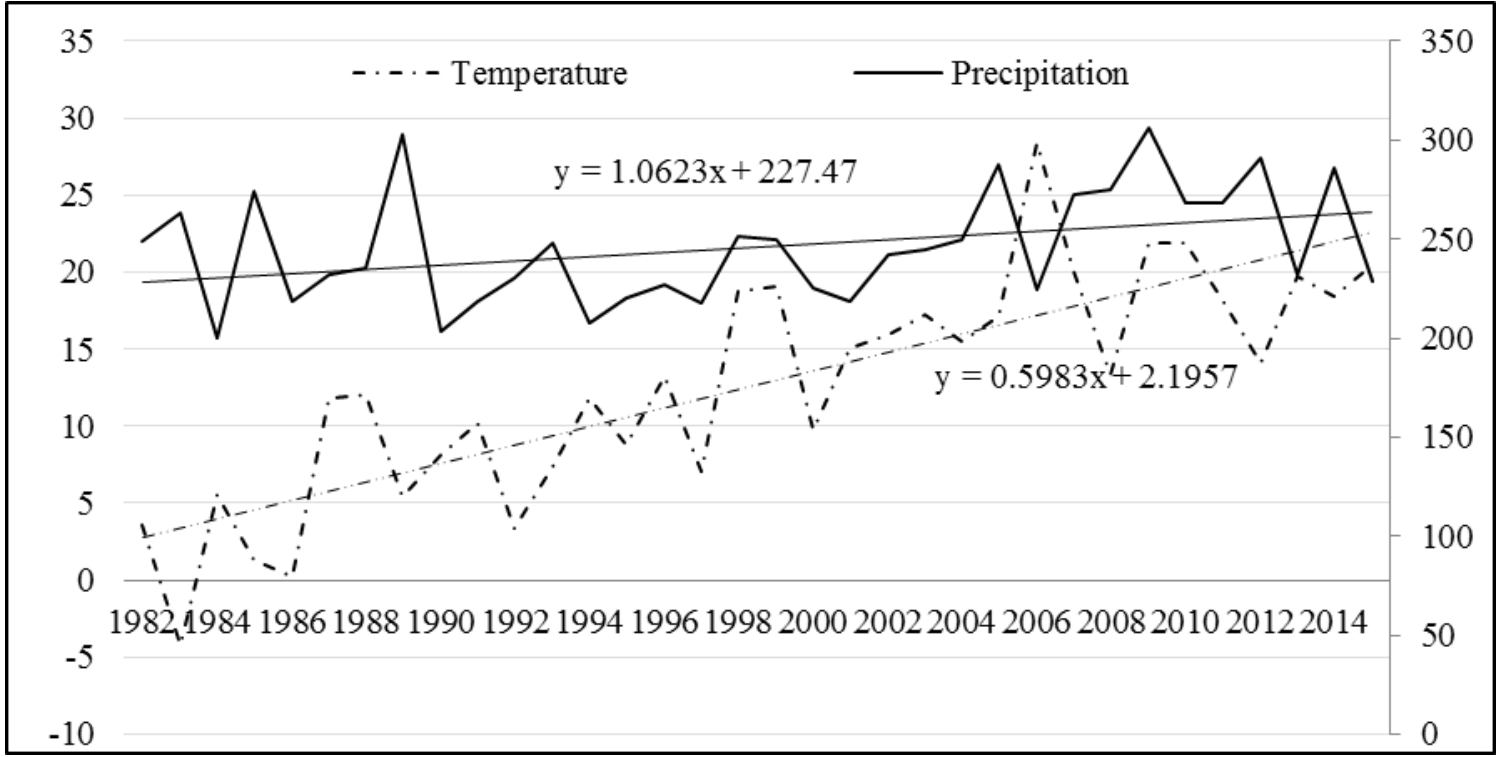

Fig.5 Changes of the Average Temperature and Precipitation in the Study Area from 1982 to 2015

The environmental index and ecological service value of the study area in 1980-2015 demonstrate that there were no changes in these factors for the farmland, forest land, and unused/residential land, indicating that these land use/land cover types are relatively balanced. However, the environmental index of the grassland and water areas decreased and the ecological service value of the forest land, grassland, and water areas decreased, indicating that the environment in the study area is deteriorating. Driven by various factors such as human activities, policy regulation, and climate change, the Qinghai-Tibet Plateau faces ecological and environmental problems such as grassland degradation, soil erosion, serious pests and diseases, increased disasters, and wetland atrophy. LUCC directly affects regional environmental changes. In the future, we should more actively optimize the land use structure, increase the restoration of the environment, and promote the sustainable development of humans and the global environment.

\section{CONCLUSIONS}

This study analyzed the LUCC and its characteristics in Qinghai Province and determined the driving factors and environmental effects of LUCC using 1:100,000 land use data from 1980 to 2015. The following conclusions are drawn:

(1) There was a significant difference in LUCC before and after 2000 in the research area. After 2000, the farmland areas did not increase significantly and the initial decrease in the water area changed into an increasing trend; the unused land area decreased and the area of residential land increased significantly.

(2) The relative change in the grassland areas was largest between 1980 and 2015 and was $1097 \mathrm{~km}^{2}$ in 1980-2000 and $1,691 \mathrm{~km}^{2}$ in $2000-2015$. Most of this area was converted into farmland, residential land, and unused land. Grassland degradation has increased during the study period.

(3) There was large spatial heterogeneity in the vegetation cover and the land use/land cover in the study area. In some areas, the FVC decreased due to the degradation of grasslands 
but in other areas, the FVC increased significantly due to policies and climate change.

(4) The environmental index of the grassland and water areas decreased and the ecological service value of the forest land, grassland, and water also declined. Overall, the environmental quality in the study area deteriorated and it is necessary to focus on ecological restoration actively and effectively.

\section{ACKNOWLEDGEMENTS}

This study was supported by the natural science foundation of Qinghai science and technology agency of China (No. 2017-ZJ744), chunhui planning project of the education ministry of China (No. Z2016076), the National Natural Science Foundation of China (No. 41162012).

The authors' gratitude goes to Professor Hu Xiasong from Qinghai University who gave constructive guidance and valuable revision of the manuscript.

\section{REFERENCES}

Batu, G., Ding, J., \& Li, Y. (2018). Land Use/Land Cover Change and Its Environmental Effects in Ugan-Kuqa River Delta Oasis. Acta Agrectir Sinica, 26(01), 53-61.

Cannone, N., Sgorbati, S., \& Guglielmin, M. (2007). Unexpected impacts of climate change on alpine vegetation. Frontiers in Ecology \& the Environment, 5(7), 360-364, doi:10.1890/1540-9295(2007)5[360:uiocco]2.0.co;2.

Cao, J., Yeh, E. T., Holden, N. M., Yang, Y., \& Du, G. (2013). The effects of enclosures and land-use contracts on rangeland degradation on the Qinghai-Tibetan plateau. Journal of Arid Environments, 97(97), 3-8, doi:10.1016/j.jaridenv.2013.05.002. Cheng, K. S., Su, Y. F., Kuo, F. T., Hung, W. C., \& Chiang, J. L. (2008). Assessing the effect of landcover changes on air temperatu $\times$ re using remote sensing images - A pilot study in northern Taiwan. Landscape \& Urban Planning, 85(2), 85-96, doi:10.1016/j.landurbplan.2007.09.014.

Cui, Q. H., Jiang, Z. G., Liu, J. K., \& Jian-Ping, S. U. (2007). A Review of the cause of rangeland degradation on Qinghai-Tibet Plateau. Pratacultural Science.

Flamenco-Sandoval, A., Ramos, M. M., \& Masera, O. R. (2007). Assessing implications of land-use and land-cover change dynamics for conservation of a highly diverse tropical rain forest. Biological Conservation, 138(1), 131-145, doi:10.1016/j.biocon.2007.04.022.

Freitas, M. W. D. D., Muñoz, P., Santos, J. R. D., \& Alves, D. S. (2018). Land use and cover change modelling and scenarios in the Upper Uruguay Basin (Brazil). Ecological Modelling, 384, 128-144, doi:10.1016/j.ecolmodel.2018.06.009.

Gou, X., Chen, F., Jacoby, G., Cook, E., Yang, M., Peng, J., et al. (2010). Rapid tree growth with respect to the last 400 years in response to climate warming, northeastern Tibetan Plateau. International Journal of Climatology, 27(11), 1497-1503, doi:10.1002/joc.1480.

Harris, R. B. (2010). Rangeland degradation on the QinghaiTibetan plateau: A review of the evidence of its magnitude and causes. Journal of Arid Environments, 74(1), 1-12, doi:10.1016/j.jaridenv.2009.06.014

Hoffmann, W. A., \& Jackson, R. B. (2000). Vegetation-Climate Feedbacks in the Conversion of Tropical Savanna to Grassland. Journal of Climate, 13(9), 1593-1602, doi:10.1175/15200442(2000)0132.0.CO;2.

Jevrejeva, S., Moore, J. C., \& Grinsted, A. (2010). How will sea level respond to changes in natural and anthropogenic forcings by 2100 ?
Jiang, Y., Liu, J., Cui, Q., Xianghua, A. N., \& Chunxu, W. U. (2011). Land use/land cover change and driving force analysis in Xishuangbanna Region in 1986-2008. Frontiers of Earth Science, 5(3), 288-293, doi:10.1007/s11707-011-0180-3.

Li, Q., Sun, Y., Yuan, W., Lyu, S., \& Wan, F. (2017). Streamflow responses to climate change and LUCC in a semi-arid watershed of Chinese Loess Plateau. Journal of Arid Land, 9(4), 609-621, doi:10.1007/s40333-017-0095-2.

Li, Q., Zhang, C., Zhou, N., \& Shen, Y. (2018). Spatial Distuibution of Aeolian Desertification on the Qinghai-Tibet Plateau. Journal of Desert Research, 38(04), 690-700.

Li, X.-L., Gao, J., Brierley, G., Qiao, Y. M., Zhang, J., \& Yang, Y. W. (2013). Rangeland Degradation On The Qinghai-Tibet Plateau: Implications For Rehabilitation. Land Degradation \& Development, 24(1), 72-80, doi:10.1002/ldr.1108.

Liu, B., You, G., Li, R., Shen, W., Yue, Y., \& Lin, N. (2015). Spectral characteristics of alpine grassland and their changes responding to grassland degradation on the Tibetan Plateau. Environmental Earth Sciences, 74(3), 2115-2123, doi:10.1007/s12665-015-4196-y.

Liu, X. D., \& Chen, B. D. (2015). Climatic warming in the Tibetan plateau during recent decades. International Journal of Climatology, 20(14), 1729-1742, doi:10.1002/10970088(20001130)20:14<1729::aid-joc556>3.0.co;2-y.

Luo, K. S., \& Tao, F. L. (2018). Sensitivity of Runoff to LUCC and Climate Change in the Heihe River Basin. Arid Zone Research.

Munsi, M., Malaviya, S., Oinam, G., \& Joshi, P. K. (2010). A landscape approach for quantifying land-use and land-cover change (1976-2006) in middle Himalaya. Regional Environmental Change, 10(2), 145-155, doi:10.1007/s10113009-0101-0.

Pinzon, J. E., \& Tucker, C. J. (2014). A Non-Stationary 19812012 AVHRR NDVI 3g Time Series. Remote Sensing, 6(8), 6929-6960, doi:10.3390/rs6086929.

Richardson, A. D., Keenan, T. F., Migliavacca, M., Ryu, Y., Sonnentag, O., \& Toomey, M. (2013). Climate change, phenology, and phenological control of vegetation feedbacks to the climate system. Agricultural \& Forest Meteorology, 169(3), 156-173, doi:10.1016/j.agrformet.2012.09.012.

Ruelland, D., Tribotte, A., Puech, C., \& Dieulin, C. (2011). Comparison of methods for LUCC monitoring over 50 years from aerial photographs and satellite images in a Sahelian catchment. International Journal of Remote Sensing, 32(6), 1747-1777, doi:10.1080/01431161003623433.

Tang, L., Dong, S., Sherman, R., Liu, S., Liu, Q., Wang, X., et al. (2014). Changes in vegetation composition and plant diversity with rangeland degradation in the alpine region of Qinghai-Tibet Plateau. Rangeland Journal, 37(1), 107, doi:10.1071/RJ14077.

Wang, T. Study of the Human-Driven Mechanism of LUCC in the Shenfu Mining Area, NW of China. In IOP Conference Series: Earth and Environmental Science, 2018. doi:10.1088/1755-1315/128/1/012133.

Xie, G., Lu, C., Leng, Y., \& Zhang, D. (2003). Ecological assets valuation of the Tibetan Plateau. Journal of Natual Resourses, 18(2), 189-196.

Xu, K. (2017). Review of Land Use/Cover Change (LUCC) Impact on the Ecological Environment. Energy \& Energy Conservation.

Zhang, J., Meng, F., Bao, A., Li, C., Qi, X., Liu, T., et al. (2018). LUCC Analysis of the Upstream of the Kongqi River,Xinjiang,China. Journal of Desert Research.

Zhang, W., Yi, Y., Jafarov, E. E., Yang, K., Kimball, J. S., \& Song, K. Simulation of Permafrost and Seasonally Frozen Ground Conditions and their Response to Recent Climate Warming in the Tibetan Plateau. In AGU Fall Meeting, 2015 
The International Archives of the Photogrammetry, Remote Sensing and Spatial Information Sciences, Volume XLII-3/W10, 2020 International Conference on Geomatics in the Big Data Era (ICGBD), 15-17 November 2019, Guilin, Guangxi, China

Zhang, Y., Wang, Z., Wang, X., \& Ding, M. (2013). Land cover changes in the key regions and self reflection on ecological construction of the Tibetan Plateau. Chinese Journal of Nature, 35(03), 187-192.

Zhao, J., \& Zhang, X. (2018). An Adaptive Noise Reduction Method for NDVI Time Series Data Based on S-G Filtering and Wavelet Analysis. Journal of the Indian Society of Remote Sensing, 46(12), 1975-1982, doi:10.1007/s12524-018-0855-2.

Zhao, L., Ran, D., \& Moore, J. C. (2016). The High Mountain Asia glacier contribution to sea-level rise from 2000 to 2050. Annals of Glaciology, 57(71), 223-231,
doi:10.3189/2016AoG71A049.

Zhao, Z., Luo, Y., \& Huang, J. (2018). Review IPCC 30 years (1988-2018). Advances in Climate Change Research, 14(05), $540-546$.

Revised September 2019 